\title{
CRONOLOGIA GERAL DA OBRA DE MARIO DE ANDRADE PUBLICADA EM VOLUME
}

\author{
TELÊ PORTO A. LOPEZ
}

\section{- Cronologia da Edição \\ - Cronologia da Composição}

Esta cronologia pretende organlzar, por generos e data de composicano, os trabalhos de Mário de Andrade publicados em volume, até 1968. Surgiu da necessidade de um panorama cronológico geral que concorresse para o estudo da obra e das idelas do escritor. Tem pols, como objetlvo, proporclonar o confronto entre as diferentes etapas do pensamento artístico e critico de Mário de Andrade, expressas através dos gêneros que ele percorreu em sua vida literária.

A relação dos trabalhos publicados em volume e o primelro passo da organtzacão cronológica geral da obra de Márlo de Andrade que deverá ser completada pròximamente com a reuniăo dos Esparsos, após o término de pesquisa com essa finalidade que está sendo desenvolvida nos perlódicos que receberam a colaboracăo do escritor.

A presente cronologla da obra editada está divldida em dols campos: a edicano e a composição. Para ambos, fol de grande valla o auxillo de uma pequena cronologla manuscrita, do próprio punho de Márlo de Andrade, encontrada entre seus papéls. Por ela e pelas datas de producāo menclonadas na malorla dos trabalhos publicados fol possivel, dentro da divisão de assuntos e gêneros, chegar ao panorama geral da composiçăo.

Na classificacão da obra de Mário de Andrade por assuntos fol empregada a expressāo "Arte Literária", ao invés de "Literatura", obedecendo-se a conceltuacão do próprio escritor, para quem a criaçăo literárla também deve ser chamada Arte. Essa divisăo nāo engloba entretanto, na ediç̄o ou na composicãa, as cartas que o autor de Macunaima tem editadas. Elas serăo objeto de outro trabalho nosso.

Em suma: esta cronologla é apenas elemento auxillar para estudos de Literatura e por essa razāo năo pretende esgotar as exigênclas do trabalho blbllográfico. 


\section{CRONOLOGIA DA EDIÇÃO}

\section{ARTE ITIYHRARIA}

a) CONTO:

\section{1 - PRIMITIRO ANDAR}

1.A ed.: Casa Ed. Antonio Tisı - Săo Paulo ................. 1926

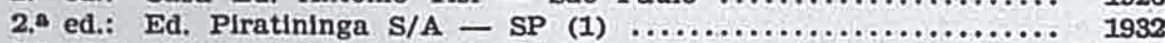

3." ed.: «Contos Selecionados do Primelro Andar - Edlcăo das Obras Completas de Mário de Andrade - parte II - vol. I «Obra Imaturas - Livraria Martins Editora - SP (2) ..... 1943

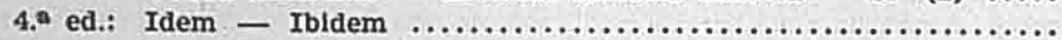

2 - belazarife ou Contos DE bellazarte, a partir de 3. a edição

$1 .{ }^{4}$ ed.: Ed. Piratininga S/A. - SP (3) $\ldots \ldots \ldots \ldots \ldots \ldots \ldots \ldots \ldots . \ldots 1934$

2.^ ed.: Americ-Edit. - Rlo de Janeiro ...................... 1944

3. ${ }^{\wedge}$ ed.: Ed. das Obras Completas de Mário de Andrade - vol. v - L. Martins Ed. - SP

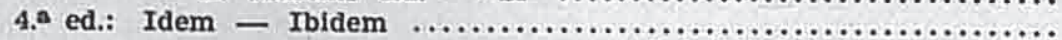

Traduono:

NIZIA FIGUFIRA, POR VOUS SERVIR, de Juan Liscano cLes 20 mellleures nouvelles de l'Amérique Latinas - Ed. Seghers - Vichy - 1958 - pp. 71 a 84.

(1) A primeira edicāo fol seguida de uma falsa segunda, resultado da propaganda e da escamoteacāo da casa editora, conforme Mário de Andrade acusa na página de aute-rosto do exemplar que incluiu em sua biblloteca:

eEsta pseudo-segunda ediçáo é falsa. São os exemplares sobrados da primeira que o editor para efeitos de publicidade capa nova. (a.) M.A.s

A página de rosto recebeu a data: 1932.

(2) Chamamos aqui de $3 .^{\text {a }}$ edicāo para auxillar a cronologia. Trata-se, como sabemos e Mário de Andrade o diz introduzindo a tiragem da obra em 1943 da como da edicăo real. Da edicão de 1943 foram retirados pelo Autor: eCocoricós segunda edicáo real. Da edicáo de 1943 foram retirados pelo Autor: «Cocoricós e ePor traz da portas, porque considerava esses contos euma vergonhas. Na mesma ocaconto \&O Bezouro e a Rosas ou \&A Primeira História de Belazartes fol transferido conto
para a obra Belazarte.

(3) Os Contos de Belazarte, segundo informacāo da eBibliografias no final do volume da primeira edição, foram destinados inicialmente a eservirem de intermédios a umas crônicas de Belazarte na 'América Brasilelra'. Entre cada cinco cronicas era intercalado um conto. Assim foram publicados os dols primeiros: co Bezouro e a Rosas (América Brasileira de fevereiro de 1924) e caim Caim e o resto u a a Rica de camaradagem me obrigaram a sair da revista, que aliás morreu $10 . .$. . 1mpulsos

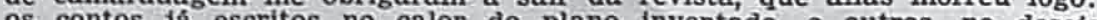
os constes, alguns tiveram realizacau e vão também aqui. ¿O Bezouro e a Rosas fol ainda publicado sem as restriçóes de revista, no livro Primeiro Andar, como página de encêrro. O <Caso em que entra bugres, escrito aliás muito posteriormente e fora do plano, fol publicado no numero de 14 de julho de 1929 , do Diário Nacional de Sáo Paulo. O conto cMenina de olho no Fundos, fol publicado no n.o 6 da Revista Nova de São Paulo.s

Por não fazer parte do plano inicial, «Caso em que entra bugres fol excluído da obra a partir da $2 . a$ ediçáo, pelo Autor. 


\section{3 - Contos novos}

1." ed.: Ed. das Obras Completas de Mário de Andrade - vol. XVII

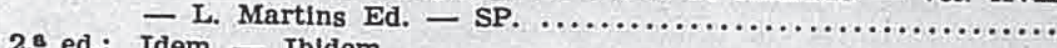

b) CRONICA:

\section{$1-$ OS FUHOS DA CANDLNHA}

1." ed.: L. Martins Ed. - SP.

- L. Martins Ed. - SP.

c) POESIA

1 - HA UMA GOTA DE SANGUE FM CADA POEMA (sob o pseudónimo de MARIO SOBRAL)

1. ed.: Ed. de Pocai \& Cla. - SP. ...................... 2." ed.: Parte I de «Obra Imaturas - vol I da Ed. das Obras Completas de Mário de Andrade - L. Martins Ed. - SP. ......

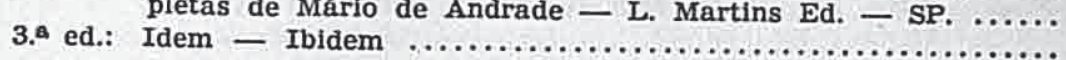

\section{2 - PAULICeIa DESVATRAda}

1. ${ }^{a}$ ed.: Com ilustraçāo de A. Moya - Ed. da Casa Mayença - SP. 1922

2.a ed.: Parte I de sPoesiass - L. Martins Ed. - SP. (4) ....... 1941

3. ${ }^{\text {B }}$ ed.: Parte I de «Poesias Completas - Ed das Obras Completas

de Mário de Andrade - vol. II - L. Martins Ed. - SP. ... 1945

$4 .{ }^{\mathrm{a}}$ e $5 . \mathrm{s}$ eds.: Idem - Ibidem $\ldots \ldots \ldots \ldots \ldots \ldots \ldots \ldots \ldots \ldots \ldots 1955-1967$

3 - LOSANGo CAQUI Ou AFETOS MUTTARES DE MUSTURA COM OS PORques DE FU SABER ATFMa - Capa de DI Cavalcanti.

1." ed.: Casa Ed. António Tisi - SP.

2. ${ }^{a}$ ed.: Alguns poemas reproduzidos na parte $I$ de ePoesiass

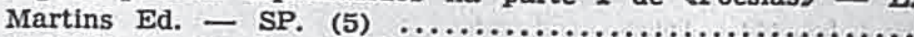

3. a ed.: Parte II de «Poesias Completas - Ed. das Obras Completas de Mário de Andrade - vol. II - L. Martins Ed. - SP.

\section{4 - CL. DO JABOTI}

1.a ed.: Ed. Piratininga S/A - SP.

2." ed.: Parte II de ePoesias poemas - L Martins Ed -

3.a ed.: Parte III de «Poeslas Completas» - Ed. das Obras Completas de Mário de Andrade - vol. II - L. Martins Ed. - SP. 1945 4. ${ }^{\mathrm{a}}$ e 5.8 eds.: Idem - Ibldem ........

(4) Os poemas de Paulicéia Desvairada que fazem parte de Poesias estāo relacionados na ¿Cronología da Composicāos, neste trabalho. Alf podem ser reconhecidos pelas iniciais da obra de que fazem parte, à direita.

(5)-(6) Vale a mesma explcacăo anterior. 


\section{5 - REMATE DE MaMFS}

1.A ed.: Estab. Gráfico Eugenio Cupolo - SP

3." ed.: Parte IV de «Poeslas CPoeslass - L Martins Ed. - SP. 1941 de Márlo de CPoesias Completas - Ed. das Obras Completas

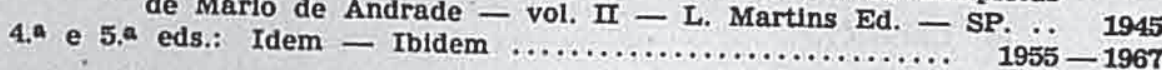

6 - POESIAS - Composto pelas partes:
1. Losango Caqui
2. Cla do Jaboti
3. Remate de Males
4. A Costeln do Grìo Căo
5. Livro Azul
L. Martins Ed. - SP. (7)

\section{7 - O CARro DA MUSERIA}

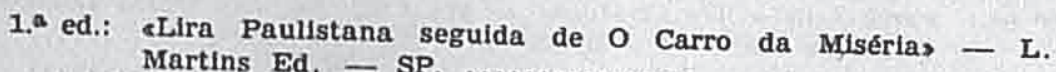

\section{8 - POESIAS COMTHETAS}
1. Paullcéia Desvairada
2. Losango Caqul
3. Clã do Jnboti
4. Remate de Males
5. O Carro da Miséria
6. A Costela do Grä Cão
7. Livro Azul
8. Lira Paulistana
9. O Café

1.4 ed.: Ed. das Obras Completas de Mário de Andrade - L. Mar-

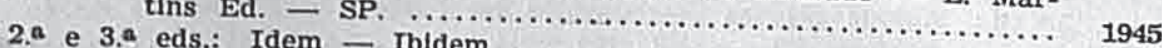

1955-1967

d) ROMANCE:

\section{1 - AMAR, Verbo INTRANSITIVo (Idilio)}

1. ed.: Casa Ed. António Tisi - SP.

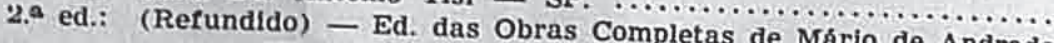

3.a e 4,a eds.: Idem - L. Martins Ed. - SP. ............... 1944 Tradueñ :

KFRAULEIN》, por Margareth Richardson Hollingsworth Macaulay - New York

(7) «A Costela do Grão Căos e «Livro Azuls nunca foram publicaçōes au- 


\section{2 - MACUNATMA, O HFROI SEM NENHUM CARATER}

1. ed.: Estab. Grár. Eugenio Cupolo - SP.

2.. ed.: (Refundido) - Liv. José Olympio Ed. $-\mathrm{RJ} \ldots \ldots \ldots \ldots \ldots$

3.a ed.: Ed das Obras Completas de Mário de Andrade - vol. IV

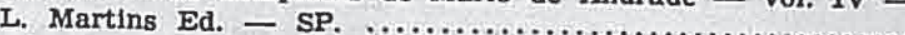

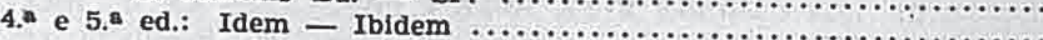

Edicãa de Luxo: 11.^ publlcacão dos 199 Blbliófilos do Brasil com ilustracões de Caribé (desenhos feitos entre 1945-1946, aprovados por Mário de Andrade) - Country Club - Rio de Janeiro, 12 de dezembro de 1957.

\section{ESTUDOS}

FOLCLORE E MÓSICA:

Ediçōes várias:

\section{1 - ENSAIO SOBRE A MUSICA BRASIHEIRA}

1.^ ed.: Ir. Chiarato \& Cla. - SP.

\section{2 - COMPENDIO DE hISTORIA DA MOSICA}

1.8 ed.: Ir. Chiarato \& Cia. - SP.

2.a ed. LG Miranda $\mathrm{Ed}$.

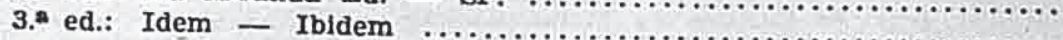

3 - MODINHAS IMPERIAIS - eEnsaio histórico e bibliográfico seguido de uma Antologia de Modinhas do tempo do Impérios.

1.A ed.: LG Miranda - SP.

4 - MOSiCA, DOCE MOSICA - EEstudos de critica e Folclores - (Subtítulo das duas primeiras ediçōes).

1. ${ }^{\circ}$ ed.: LG Miranda - SP.

de rosto)

(capa) $\quad \ldots \ldots \ldots \ldots \ldots \ldots \ldots \ldots \ldots \ldots \ldots$ 5 - LUCIANo GAWLET - Introdução aos «Estudos de Folclore de Lu-
ciano Gallet».

1." ed.: Carlos Wehrs \& Cia. - RJ.

g-CUltura musical - Orasão de paraninfo - (opúsculo).

1." ed.: Separata da eRevista do Arquivo Municipals - Ed. de Dep. de Cultura da Prefeitura de São Paulo - SP.

7 - A MOSICA E A CANCAO POPULARES NO BRASU - EEnsaio critico-bibliográficos.

1.^ ed.: Separata da eRevista do Arquivo Municipals - n.0 19 - Ed. do Dep. de Cultura da Prefeltura de Sāo Paulo - SP ...... 
- Mimeografada como boletim e distribuida pela D. de Coop. Intelectual do Minlstérlo das Relacóes Exterlores - RJ. ....

Traducão:

1. KILA CANOTON Y LA MUSICA POPULARES EN FL BRAsIC (opúsculo) - Pub. do Consulado Brasileiro em

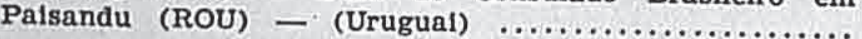

2. Traduclo francêsa in FOLCLORE MUSICAL - Inst. Intern, de Coop. Intélec. - Parls (8) ...............

3. LA MUSIOA Y LA CANCION POPULARES EN EL BRAsIL - Trad. de Alarcón Fernandez - Col. Monog. Brasileñas - Imp. Nacional - Minist. das Relaçбes Exteriores - Dep. de Coop. Intelec. - RJ ............

\section{8 - Samba ruray paUtista}

1. ${ }^{\circ}$ ed.: Separata da eRev. do Arquivo Municlpals - n.o 41, ao lado lado do estudo de Mário Wagner Vleira: «Festa de Bom Jesus de PIraporas - Dep. de Cultura da Prefeltura de Săo Paulo - SP. ........................

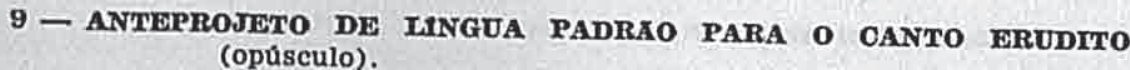

1. ${ }^{4}$ ed.: Escrito para o I Congresso da Lingua Nacional Cantada Dep. de Cultura da Municipalldade - SP. ............. 1937

10 - NORMAS PARA A PRONUNCIA DA IINGUA NACIONAL NO CANTO FRUDTTO

1.a ed.: Separata da eRevista do Arquivo Municlpal» - N.0 34 Dep. de Cultura da Munlcipalidade - SP. ...............

\section{II - OS COMPOSTMORES E A IHNGUA NACIONAL}

1." ed.: Separata dos Anals do I Congresso da Lingua Nacional Cantada - Dep. de Cultura da Munlcipalldade

12 - A PRONONCLA CANTADA E O PROBLEMa DA NASAL PELOS DIscos - «Estudo da fonacăo no canto erudito e populars.

1. ${ }^{*}$ ed.: Separata dos Anais do I Congresso da Lingua Naclonal Cantada - Dep. de Cultura da Municlpalldade - SP. ........

13 - NAMOROS COM A MEDICINA

1. Terapeutica Musical.

2. Medicina dos excretos.

1. ed.: B. de Investigaç̃o e Cultura n.0 5 - Ed. da L. do Globo - POrto - RGS

(8) Sabe-se da traducăo francesa pela lista das publicacões de Márlo de Andrade que algumas de suas obras trazlam na contra-capa ou na Mário de ê menclonado aqui o título que o ensalo recebeu em traducăo. Por essa razăo, năo 
14 - A EXPRESSAo MUSICAI NOS ESTADOS UNmOS (opûsculo)

1.^ ed.: Liçōes de Vida Americana n.0 3 - Instituto Brasil-EE.UU.

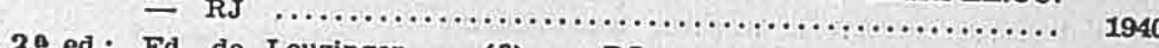

Ed. de Leuzinger $-(?)-$ RJ. $\ldots \ldots \ldots \ldots \ldots \ldots \ldots \ldots \ldots \ldots$ s/d.

Traducão:

LA GXPRESSION MUSICAL DE LOS ESTADOS UNDDOS

Coleçå: Problemas Americanos - Dir. de Newton Freitas -

Patrocinio do Escr. Comercial do Brasil-Buenos Aires .....

15 - MOSICA DO BRAST.

1. Evolucĩo Social da Música Braslleira

2. Dançs Dramáticas Ibero-Americanas

1. ${ }^{a}$ ed.: Col. Caderno Azul n.o 1 - Direcāo de S. Milliet - Plácido e Sllva - Luis Martins - Ilustração de Portinari - Ed

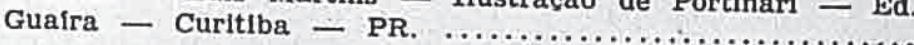

Traducão:

MrósICA DEL BRASK - trad. de Délla Bernabó - Ed. Schapire - Buenos Alres

16 - A NaU catarineta (opúsculo).

1. ed.: «Rev. do Arquivo Municipal" n.o 73 - Separata - Dep. de Cultura da Municipalidade - SP.

17 - EVOLUCÃo DE GOMES CARDIM (opúsculo).

(Dita na festa do 77.o aniversário de fundação do Conservatório, promovida pelo Centro Dramático e Musical «Gomes Cardims a 16 de setembro de 1942) - Ed. da Interventorla do Conserv. - Ind. Grár. Siquelra - sP.

18 - ATUAImADE DE CHOPIN (opúsculo).

1. ${ }^{a}$ ed.: Separata da «Rev. do Arquivo Municipals n.o 86 do Dep. de Cultura da Municipalldade de São Paulo - SP

2.a.ed.: Parte II de $₫$ O Balle das Quatro Artes - Col. Mosaico n.o 2

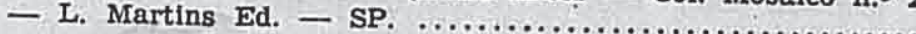

19 - O FOLCLORE NO BRASW

1." ed.: Manual Blbllográfico de Estudos Braslleiros - RJ. ....... 
Ddigão das «Obras Completas de Mário de Andrade» da Livraria Martins Edit6ra - São Panlo

1 - ENSAIO SOBRE A MUSICA BRASILEIRA

1. Ensaio sóbre a Música Brasileira

2. A Música e a Canção Populares no Brasil

$1 .{ }^{\mathrm{n}}$ ed.o Vol. IV

I962

2 - MOSICA, DOCE MOSICA

1. Música, Doce Música - critica (9).

2. A Expressáo Musical nos Estados Unidos.

$1 .{ }^{\circ}$ ed.: Vol. VII

צ - apequena historia da mosica - ampliacão e refusāo de «Compêndio de Histórla da Músicas.

1.n ed.: com tiragem especial de 30 exemplares em papel glacê capa de Clóvis Graclano .........................

Fm brochura:

1.a ed.: Vol. VII

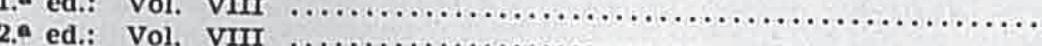

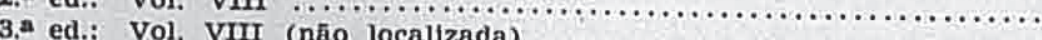

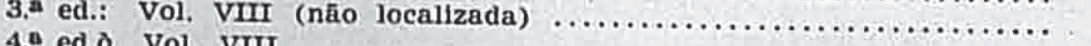

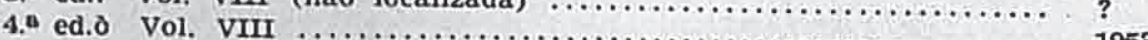

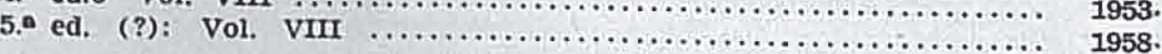

\section{4- ASPECTOS DA MOSICA BRASILEIRA}

1. Evolucão Social da Música no Brasil.

2. Os compositores a Lingua Nacional.

3. A Pronúncia cantada e o problema da nasal pelos discos.

4. O samba rural paulista.

5. Cultura . Musical.

1.^ ed.: Vol. XI

1965.

5 - MOSICA DE FEITICARIA NO BRASIL

1.a ed.: Vol. XIII

1963:

6 - DaNCas DRAMATICAS Do BRASH - 3 tomos

1.a ed.: Vol. XVIII

1959

\section{7 - MODINHAS IMPERIAIS}

1." ed.: Vol. XIX

(9) Segundo folha manuscrita de Mário de Andrade, Música, Doce Música abrangia artigos de sépocas váriass de 1924 a 1932, em sua primeirace Música 1934. Para uma segunda edicão, Mário de Andrade já organizara mácáo de artigos, posteriores a 1932. Oneyda Alvarenga, que reuniu os artigais alguns Edicito das Obras Completas obedeceu fielmente: formam a parte IV para a cArtigos Novoss, dentro da primeira parte do volume cuúsica parte segunda divisáo, AA Expressăo Musical nos Estados Unidos também fol inclúda
postumamente. 


\section{ESTUDOS}

QUATRO ARTES:

Edições várias:

I - A escrava que não e isaura - (Poética).

1. ${ }^{\circ}$ ed.: Liv. Lealdade - SP.

\section{2 - O ALEIJADINHO E ALVARES DE AZEVEDO}

1. O Aleijadinho e sua posiçao nacional.

2. Amor e Mêdo.

1. ${ }^{a}$ ed.: RA Editora - RJ.

3 - PORTINARI

1.a ed.: Catálogo - Minist. da Educação e Saúde

4 - MEMORIAS DE UM SARGENTO DE MULCIAS - Introdução critica para a Edição de Luxo da obra - Liv. Martins Ed. - SP s/d.

5 - o Movimento Modernista - Conferencla lida no Salāo de Conferencias da Bib. do Minist. das Rel. Exteriores.

1. ${ }^{a}$ ed.: Casa do Estudante no «Jornal do Comérclos - Rodrigues \& Cla. - RJ. .......................... Rodrigues

6 - ASPECTOS DA ITTERATURA BRASHGIRA

Composto pelas partes:

1. Tristão de Atafáde

2. A Poesia em 1930

3. Luis Aranha o a Poesia Preparatoriana

4. Machado de Assis

5. Castro Alves

6. Memórias de um Sargento de Mrilicias

7. A volta do Condor

8. O Ateneu

9. Elegia de Abril

1.^ ed.: Coleção Joaquim Nabuco - Americ, Ed. - RJ.

7 - Novo momonto PERnambucano - Prefáclo para poesia de Otávio de Freitas Jr.

1.^ ed.: Coleçăo Ensalos Brasileiros - Casa do Estudante - RJ. ...

8 - LASAR SEgAII (opúsculo).

1. ed.: Catálogo - Ministério da Educacăo e Saúde - RJ ....... 
Tradugão :

LASAR SEGAII OF BRAZIL - FIRST AMIFRICAN FXTBIMION - texto de Mário de Andrade e Germain Bazin Assoc. American Artists - Nova Iorque .................

3 - O Banfe das quatro artes

Composto pelas partes:

1. O artista e o artesão

2. Romantismo Musical

3. Fantasla de Walt Disney

4. Romanceiro de Lampeão

5. Candido Portinari

6. Atualidade de Chopin

1.a ed.: Coleção Mosalco - Vol. 2 - L. Martins Ed. - SP ......... s/d.

10 - PADRE JESURNO DO MONTE CARMELO

1. ${ }^{\text {ed. }}$ eRevista do SPHAN》, n.0 $14-$ RJ.

Edicão das «Obras Completas de Mário de Andrade» da Livraria Martins Editôra - Săo Paulo

1 - OBRA IMATURA

1. Há uma gôta de sangue em cada poema

2. Primeiro Andar

3. A Escrava que nīo é Isaura (poética)

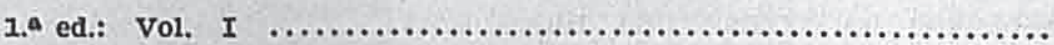

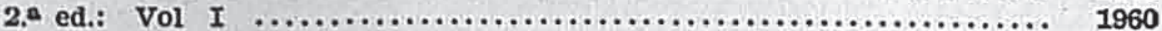

\section{2 - ASPECTOS DA MUGRATURA BRASWGIRA}

1. Aspectos da Miteratura Brasileira

2. Amor e Medo

3. O Movimento Modernista

4. Segundo Momento Pernambucano - (Novo Momento Pernambucano).

1.a ed.: vol. $\mathrm{x}$

s/d.

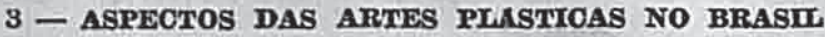
1. O Aleijadinho
2. Lasar Segall
3. Do Desenho
4. A Capela do Santo Antonio

1.a ed.: Vol. XII 
4 - O BATE DAS QUATRo amtes

1. O Balle das Quatro Artes - com os sels ensaios da 1.8 ediçăo

2. Arte Inglesa

1.a ed.: Vol. XIV

1963

\section{5 - O EMPATHADOR DE PASSARINHO}

1.A ed.: Vol. $\mathrm{Xx}$

s/d.

\section{CRONOLOGIA DA COMPOSIÇÃO}

\section{SIGLAS FMPREGADAS}

1 - EDICOES:
Americ-Edit.: Americ-Edit.
AT.: Casa Editora Antonto Tisi
E. Cupolo: Estabelecimento Gráfico Eugenio Cupolo
M.: Livrarla Martins Editora
P.: Editora Piratininga S/A.

2- OBRAS:

A - Arte Literária:

a) Conto:
PA.: Primeiro Andar
B.: Belazarto e Contos de Belazarte
CN.: Contos Novos

b) Crônica:

FC.: Os Filhos da Candinhs

c) Poesia:

\begin{tabular}{l} 
CJ.: Clñ do Jaboti \\
RM.: $\quad$ Remate de Males \\
CG.: $\quad$ A Costela do Gräo Cão \\
LA.: Livro Azul \\
CM.: O Carro da Miséria \\
PC.: \\
\hline
\end{tabular}

B - Estudos:

a) Folclore e Música:

EMrB.: Ensaio sôbre a Másica Brasllelra
NM.: Namoros com a Medicina
MDM.: Másica, Doce Másica
AMIB.: Aspectos da Másica Braslleira


b) Quatro Artes:

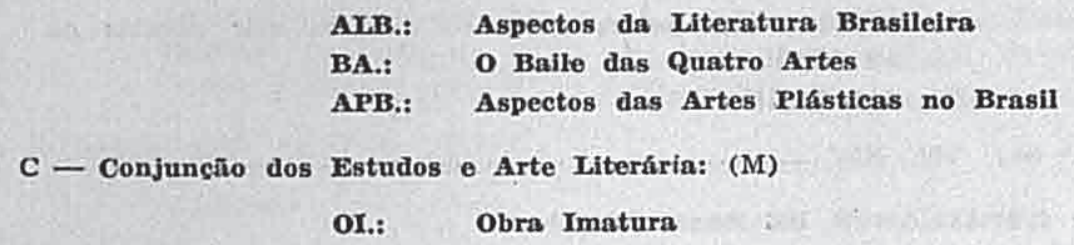

\section{ORONOLOGIA DA COMIPOSICAO}

Nota: Na impossibllidade de estabelecer a data de algum trabalho quanto à composição, usa-se a data da primeira edição com uma interrogação.

\section{A - Arte Literárin}

a) Conto:

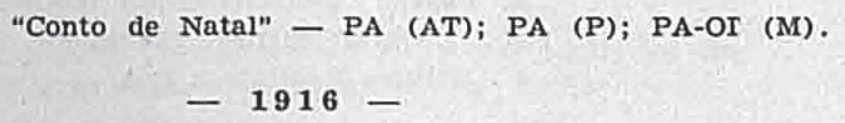

A - Arte Literáris

a) Conto:

"Cocoric6" (1) - em forma de peça teatral de 1 ato PA (AT); PA (P).

A - Arte Literaria

a) Conto: "Cacada de Macuco" - PA (AT); PA (P); PA-OI (M).

b) Poesia: "Há uma gôta de sangue em cada poema" - Pocal \& Cia. Poemas:
1. "Prefácio"
2. "Exaltaçāo da Paz"
3. "Inverno"
4. "Epitalamio"
5. "Refrāo de Obus"

(1) No final da primeira edicāo de Primeiro Andar está a nota explicativa de Mario de Andrade:

«Certas frases de «Cocoricós nāo provam absolutamente que antedatel essa chatice. Foram inseridas posteriormente no conto (sic) datel essa chatice. Foram inseridas posteriormente no conto (sic).
Que figura neste livro tal e qual alguns outros, provando a incapaci-
dade passadista minha. Năo है tanto lambugem pros inimigos, năo. dade passadista minha. Năo é tanto lambugem pros inimigos, não. jầ fol.s 

6. "Primavera"
7. "Espasmo"
8.- "Guilherme"
9. "Devastaçāo"
10. "Natal"
11. "Lovaina"
12. "Os Carnivoros"

-1918 -

A - Arto Literária

a) Conto:

"Caso Pansudo" - PA (AT); PA (P); PA-OI (M).

"O Galo que não cantou" - PA (AT); PA (P); PA-OI (M). "Por trás da porta" (1 ato) - PA (AT); PA (P).

$$
-1919-
$$

A - Arte Literária
a) Conto:

"Eva" (1 ato) - PA (AT); PA (P); PA-OI (M).

\section{A - Arte Literária}

a) Conto:

"Brasilla" - PA (AT); PA (P); PA-OI (M).

b) Poesia: "História com data" - PA (AT); PA (P); PA-OI (M).

"Paulicéla Desvairada" - composta entre dezembro de 1920 e dezembro de 1921 - C. Mayenca.

"Poesias" - parte I (M) - Cos poemas grifados na relacāo abaixo); PC (M).

Divisāo da obra:

1. Dedicatória - 14 de dezembro de 1921

2. Prefáclo Interessantissimo

Poemas:

"Artista"

"Inspiraçāo"

"O Trovador"

"Os Cortejos"

"A Escalada"

"Rua de São Bento"

"O Rebanho"

"Tlete"

"Paisagem n.०1"

"Ode ao Burguês"

"Tristura"

"Domingo" 
"O Domador"

"Anhangabaú"

"A Cacada"

"Nocturno"

"Palsagem n.० 2"

"T $T$ "

"Paisagem n.० s"

"Colloque Sentimental"

"Religīo"

"Paisagem n.० 4"

"As Enfibraturas do Ipiranga"

$$
-1922-
$$

A - Arte Literárla

a) Conto: "Moral Cotidiana" (1 ato) - PA (AT); PA (P); PA-OI (M).

b) Poesia: "Losango Cáqui" - obra escrita em 1922, segundo o Prefáclo do A. datado de 1924 - AT.

"Poeslas" - (M) (os poemas grifados na relaçăo abaixo) PC $(M)$.

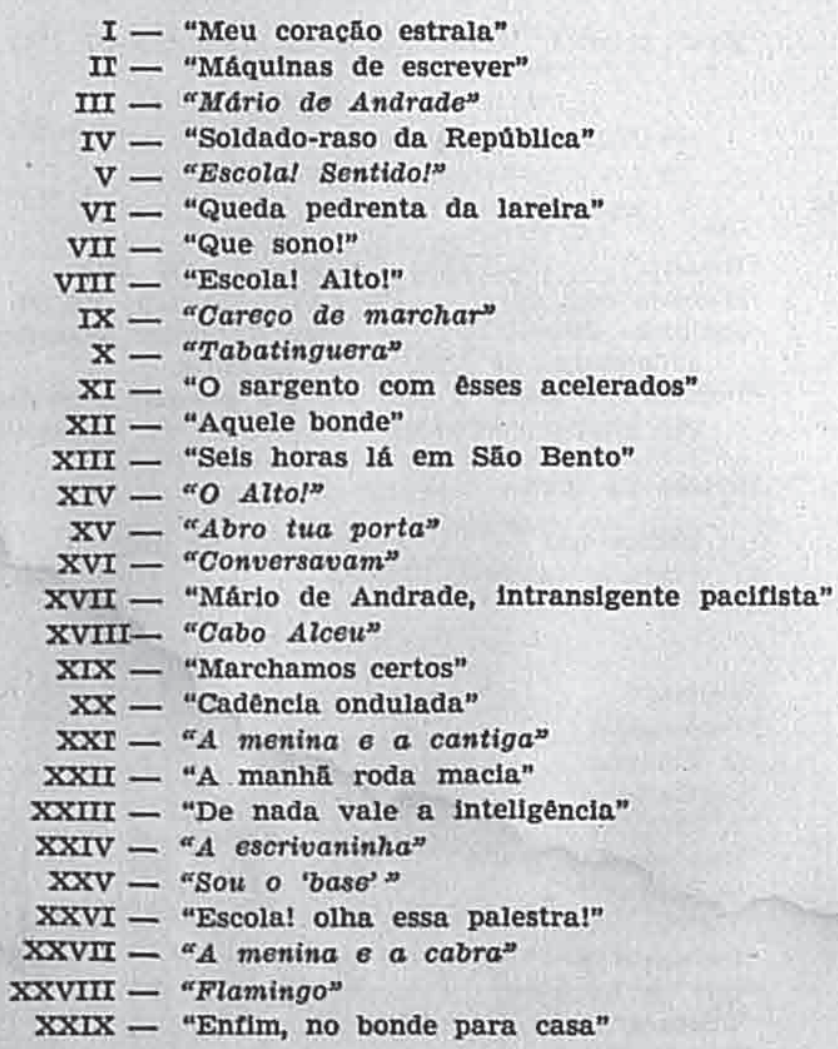




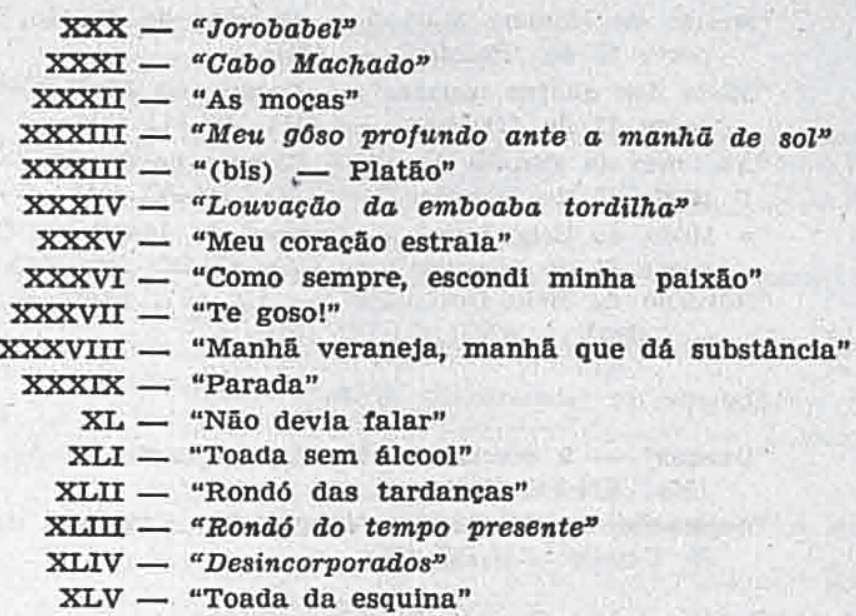

A - Arte Literária

a) Conto:

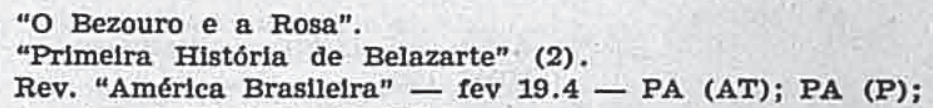

b) Poema:

"Carnaval Carioca" - CJ (P); parte II de "Poesias" (M) CJ-PC (M).

$B$ - Ensaio

Poética:

"A Escrava que não Isaura" - "Discurso sobre algumas tendenclas da poesia modernista" - L. Lealdade OI (M).

$$
\text { - 1924- }
$$

\section{A - Arte Literária}

b) Poesia: "Caim, Caim e o resto", ou "Caim, Caim, Caim" - a partir da 2. ed. - B (P); B - Americ-Ed., B (M).

"Jaburu malandro" - B (P); B - Americ-Ed.; B (M).

a) Conto: गoemas de "Clä do Jaboti":

"Rondó que eu flz para você" - CJ (P); CJ-PC (M).

"O poeta come amendolm" - CJ $(P)$; parte II de "Poesias" (M); CJ-PC (M).

(2) O conto, a partir da segunda edicăo real, fol transferldo para o seu lugar devido: a obra Belazarte. 
"Soneto do Homem Morto" - Campos do Jordāo, 1924 (3); parte II de "Poesias" - (M).

"Moda dos quatro rapazes" - Campo do Jordāo - CJ (P): parte II de "Poeslas" - (M); CJ-PC (M).

"Acalanto da Pensão Azul" - Campos do Jordão - CJ (P); parte II de "Poesias" - (M); CJ-PC (M).

"A Moda do Brigadelro" - Compos do Jordāo - CS (P) parte II de "Poeslas" - (M); CS-PC (M).

"Noturno de Belo Horlzonte" - CJ (P); parte II de "Poeslas" - (M); CJ-PC (M).

Poemas de "Remate de Males":

"Dancas" - 9 poemas - E. Cupolo; parte III de "Poesias" (M); RM-PC (M).

"Asplracāo" in "Marco de Viração" - 9 de set. de 1924 E. Cupolo; RM-PC (M).

Poema de "A Costela de Grāo Cão":

"Canto de Mal de Amor" - parte IV de "Poeslas" - (M). - GC-PC (M).

B - Ensaio

a) Música:

"O Amor em Dante e Beethoven" - MDM-LG Miranda; MDM (M).

"Reacăo contra Wagner - Estudos para uma História da Música" - MDM-LG Miranda; MDM (M).

"Marcelo Tuplnambá" - MDM-LG Miranda; MDM (M).

$$
-1925-
$$

\section{A - Arto Literária}

a) Conto:

"Menina de olho no fundo" - Revista Nova n.० 6 - B (P); B (Americ-Ed.); B (M).

"NIzla Figueira, sua crlada" - B (P); B (Americ-Ed.); B (M).

b) Poesla: Poomas de "Remate de Males":

"Improviso do rapaz morto" - in "Marco de Viração" (E. Cupolo); RM-PC (M).

"Momento" - nov. de 1925 ("Ninguém ignora a inquietacăo") - (E. Cupolo); RM-PC (M).

"Louvacăo Matinal" - (E. Cupolø); parte III de "Poesias" (M); RM-PC (M).

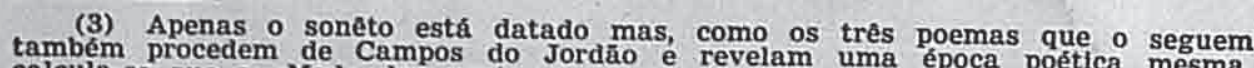
calcula-se que a «Moda dos quatro rapazess, <Acalanto da pensã poetica mesma, do Brigadelros sejam do mesmo periodo de composicão. 


\section{A - Arte Literária}

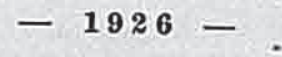

a) Conto:

"Plá nāo sofre, sofre" - B (P); B (Americ-Ed.); B (M). "Túmulo, túmulo, túmulo" $-\mathrm{B}(\mathrm{P}) ; \mathrm{B}(\mathrm{P}) ; \mathrm{B}$ (Americ-Ed.);
B (M).

b) Poesla:

Poemas de "Clä do Jaboti":

"Sambinha" - in "Coordenadas" - CJ (P); parte II de "Poeslas" (M); CJ-PC (M).

"Vluvita" (?) - Ibldem - CJ (P); CJ-PC (M).

"Lembranças do. Losango Cáqul" - Ibldem - CJ (P); CJ-PC (M).

in "Rltmo SIncopado" (CJ) - escritas entre 1923/1926:

"Arralada" - CJ (P); parte II de "Poesias" (M); CJ-PC (M).

"Toada do Pal do Mato" - CJ (P); parte II de "Poeslas" (M); CJ-PC (M).

"Tempo das águas" - CJ (P); parte II de "Poeslas" (M); CJ-PC (M).

"Poema" - CJ (P); parte II de "Poeslas" (M); CJ-PC (M).

"Tostão de chuva" - CJ (P); parte II de "Poesias" (M"; CJ-PC (M). "Lenda do céu" - CJ (P); parte II de "Poeslas" (M);
CJ-PC (M).

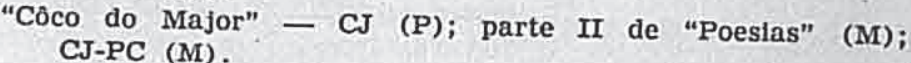

"Moda de Cadeia de Pôrto Alegre" - CJ (P); parte II de "Poesias" (M); CJ-PC (M).

"Moda da cama de Goncalo Plres" - CJ (P); parte II de "Poeslas" (M); CJ-PC (M).

"Palsagem n. 5" - CJ (P); CJ-PC (M).

in "Dois poemas acreanos" - CJ (P); parte II de "Poesias" - (M); CJ-PC (M).

"Descobrimento"

"Acalanto do seringuelro"

Poemas de "Remate de Males" in "Tempo de Maria - (E. Cupolo); parte III de "Poeslas" (M); RM-PC (M):

"A Moda do corajoso" - I

"Amar sem ser amado, ora pinhōes!" - II

"Cantiga da ai!" - III

"Lenda das mulheres do pelto chato" - IV

"Eco e o Descorajado" - V

"Louvaçäo da Tarde" - VI

"Marla" - VII

Poemas de "A Costela do Grão Cão" - parte IV de "Poeslas" - (M); GC-PC (M).

"Reconhecimento de Nemesis"

"Mãe" 
c) Romance:

"Amar, verbo intrasitivo" (4) - escrito entre 1923-1924, conforme o livro - AT (M).

B - Ensalo

a) Música:

"Critica do Gregoriano" - "Estudos para uma Histórla da Música" - MDM-LG Miranda; MDM (M).

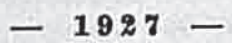

A - Arto Miterária

a) Poesla:

Poema: "Ponteando sôbre o amigo rúim" - in "Marco de viração de "Remate de Males" - (E. Cupolo); RM-PC (M).

b) Romance:

\section{Rapsódia (5):}

"Macunaima", escrito entre dez. de 1926 e Jan. de 1927, conforme indicação inicial do volume. Segundo Márlo de Andrade, escrito: "1." versăo dez. de 1926, 2." versăo Jan. e fev. de 1927 , - versăo definitiva dos três últimos meses de 1927" (6) - E. Cupolo; J. Olymplo Ed.; (M); 100 Biblioflios.

C - Critica Musical

"O pal de Xenia" - MDM (LG Miranda); MDM (M).

"Luclano Gallet, Cancōes Brasileiras" - MDM (LG Miranda) ;MDM (M).

\section{A - Arto Literária}

a) Poesia:

Poemas de "Remate de Males" in "Marco de Viracão" (E. Cupolo); parte III de "Poesias" (M); RM-PC (M). "Bodas Montevideanas" - 15 de Jan. de 1928

"A. Advinha"

"Improviso do mal da América" - fev. de 1928

"Manhä" - 18 de mar. de 1928

"Pela nolte de barulhos espacados" - jun. de 1928

(4) A data de composicăo é fornecida pelo Autor em suas páginas manuscritas de Cronologia: 1926.

(5) A classificaç̃o de Mracunaíma como romance no sentido culto do gênero E nossa. Mário de Andrade a empregou no sentido folclórico, conforme explica nas cartas a seus amigos e nos anúnclos de Macunaima em julho de 1928, no Dlário Nacional de Sáo Paulo. Por essa razăo chamou a obra, «rapsódias.

(6) Segundo a cronologia manuscrita do Autor. 
Poemas de "A Costela do Grão Cão" - parte IV de "Poesias" (M); GC-PC (M).

"Lundu do escritor dificil"

"Melodia Moura"

"Momento" ("Deve haver aqui perto...") - 16 de set. de 1928

b) Cronica:

"O Grande Cearense" (?) selecionada por Márlo de Andrade em 1942 para FG (M).

B - Critica Musical

C - Ensalos

"Contra as temporadas liricas" - I a VII (7) - MDM (LG Miranda); MDM (M).

a) Artes Plásticas:

b) Música:

"O Aleljadinho e sua posição naclonal" ou "O Aleijadinho", na ediçāo da L. Martins Ed. - In "O Aleljadinho Alvares de Azevedo" - RA Editora; APB (M).

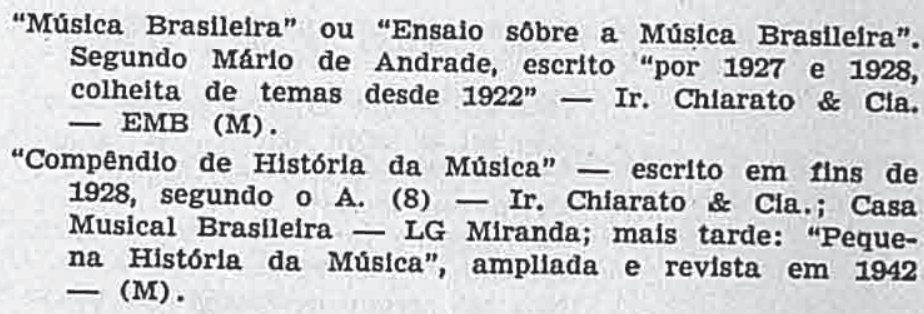
Segundo Márlo de Andrade, escrito "por 1927 e 1928 colneita de temas desde 1922" - Ir. Chlarato \& Cla. - EMB (M).

"Compendio de História da Música" - escrito em fins de 1928, segundo o A. (8) - Ir. Chiarato \& Cla.; Casa Musical Braslleira - LG Miranda; mals tarde: "Pequena Histórla da Música", ampliada e revista em 1942 $-(M)$.

D - Folclore

Artigos:

"Romance de Veludoo" - MDM-LG Miranda; MDM (M). (9)

"Lundu de Escravo" - MDM-LG Miranda; MDM (M). (10)

$$
-1929-
$$

A - Arte Literária

a) Conto:

$$
\begin{aligned}
& \text { "Caso em que entra bugre" - } 14 \text { de jul. de } 1929 \text { - "Diárlo } \\
& \text { Naclonal" - SP; B (P). (11) }
\end{aligned}
$$

(7) No livro da Livraria Martins nāo há indicação do periódico em que as Díric Naclonal de Săo paulo. primelra vez, mas a pesquisa póde localizá-la no Naclonal de Săo Paulo.

(8) Segundo a cronologia manuscrita do Autor.

respectivamente

11) O conto fol excluido do livro pelo Auotr, a partir da $2 .{ }^{a}$ edicăo. 
b) Crônica:

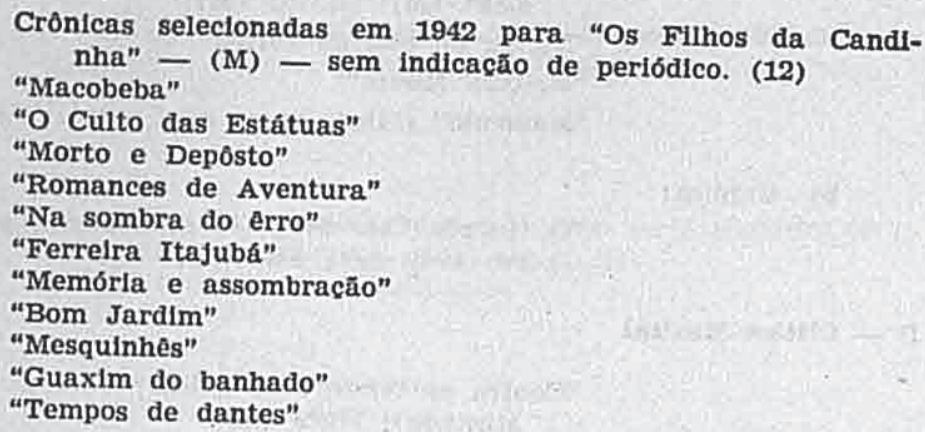

c) Poesla:

Poemas de "Remate de Males" - (E. Cupolo); parte III de "Poeslas" - (M); RM-PC (M).

"Eu sou trezentos..." - 7 de jun. de 1929

in "Poemas da Negra" RM:

"Nāo sel porque espirito antigo - I

"Não sel se estou vivo" - II

"Voce é tão suave" - IIT

"Estou com médo" - IV

"Lá longe no sul" - V

"Quando..." - vI

"Năo sel porque os teteus" - VII

"Nega em teu ser primárlo" - VIIr

"Na zona da mata" - IX

"Al momento de físico amor" $-\mathrm{XI}$

"Lembranca boa" - XII

In "Poemas da Amiga" - RM (1929-1930):

"A tarde se deltava nos meus olhos" - I

"Si acaso a gente se beijasse uma só vez" - II

"Agora é abril" - III

"Oh trágico fulgor" - IV

"Contam que lá nos fundos" - V

"Nós lamos calados pela rua" - VI

"E hora. Mas é tal..." - VII

"E uma pena, doce amiga" - VII (bis)

"Gosto de estar ao teu lado" - VIII

"Vossos olhos sāo o mate costumelro" - IX

"Os rios, ó doce amiga..." - X

"A rebre tem um vigor..." - XI

"Minha cabeca poisa..." - XII 
B - Critica Musical

Artigos sem indicacão de periódico selecionados pelo A.
para "Música, Doce Música" - LG Miranda e repetidos em MDM (M):

"Camargo Guarnieri: Sonatina"

"Campanha contra o trust dos comerciantes de música" 6 artigos

"Amadorismo profissional"

C - Ensaio

a) Folclore:

"A Influência portuguésa nas rodas infantis" - Memória para o Congresso Internacional de Arte Popular de Praga - MDM-LG Miranda; MDM (M).

\section{A - Arte Literária}

a) Conto:

"Os sírios" - fragmento do romance inconcluso "Café" PA (OI (M).

b) Crônica:

Crônicas selecionadas pelo A. em 1942 para FC (M), sem indilcação de periódico. (13)

"Educai vossos pals"

"A pesca do dourado"

"Anjos do Senhor"

"Revoluç̄o pascácia"

"Xará, xarapim, xêra"

"A Sra. Stevens"

"Ensalo Bibllothèque Rose"

B - Critica Musical

Artigos sem indlcacão de periódico, selecionados pelo A. para "Música, Doce Música" - LG Miranda e repetidos em MDM (M)

"Dinamogenias politicas"

"Villa Lobos versus Vila Lobos" - 6 artigos respectivamente datados em 1930:

15 de Juiho

29 de julho

27 de agôsto

2 de setembro

25 de setembro

2 de dezembro

"Luta pelo Sinfonismo" - 14 artigos:

I - "Decadencla": 19 de marco; 


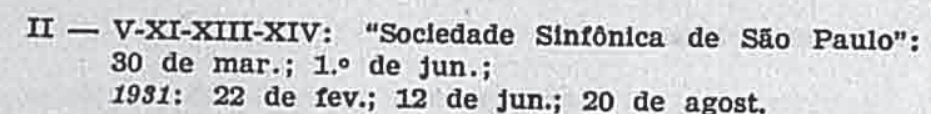
III - IV-VI a X-XII: "Socledade de Concertos Sinfonicos": 9 de abr.; 4 de mal.; 5 de agost.; 4 de out.; 1931: 3 de rev.; 10 de lev.; 19 de rev.; 26 de mar.

C - Ensaio

a) Folclore:

"Origens do Fado" - MDM (LG Miranda); MDM (M).

b) Música:

"Pe. José Mauriclo" - MDM (LG Miranda); MDM (M).

"Modinhas Imperlals" - obra escrita, segundo o A., em abrll de 1930, mas com colhelta de documentos felta desde 1917, mais ou menos. - (C. Chlarato); (LG Miranda); (M).

\section{A - Arte Ilterária}

a) Cronica:

Crónicas seleclonadas em 1942 pelo A., para FC (M) sem Indicacão de períodlico (14):

"O Dlabo"

"O Sobrinho de Salome"

"O terno itinerário ou trecho de antologia"

"Meu engraxate"

"Fábulas"

"Meu secreta"

b) Poesia:

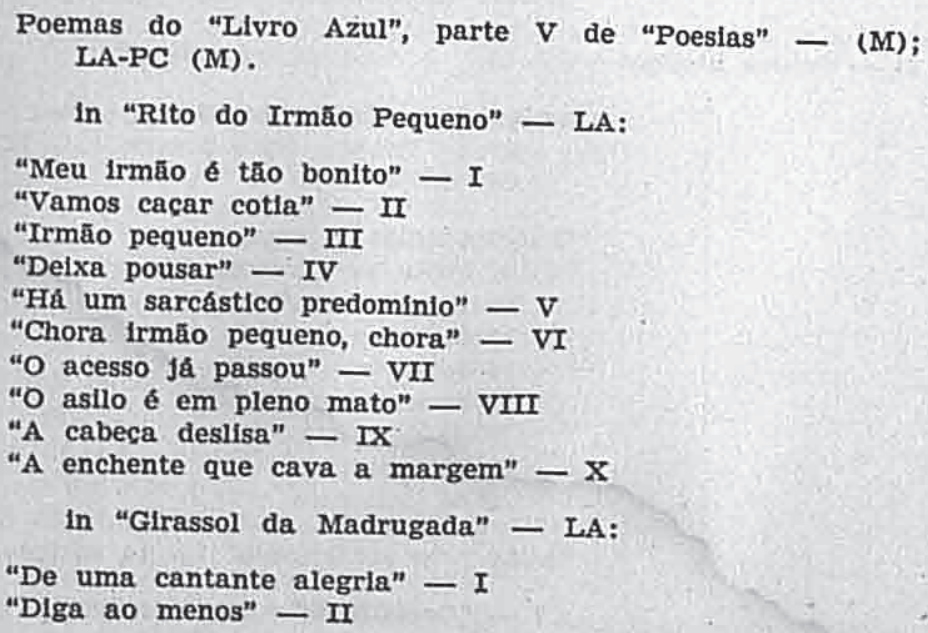


"Si o teu perfil" - III

"Não abandonarel jamais" - IV

"Teu dedo curioso me segue" -

"VI os trens de ferro" - VI

"A noite se esval lá fora" - VII

\section{B - Critica Musical}

Artigos selecionados pelo A., sem indicacão de perí́dico para "Música, Doce Música" (LG-Miranda) e repetidos em MDM (M) :

"A Música no Brasil"

"O Teremin"

"Henrique Oswald"

"Lorenzo Fernandez: Sonatina"

"J. A. Ferrelra Prestes"

"Germana Bittencourt"

"P.R.A.E." - 5 artigos: 4 de jan.; 6 de jan.; 7 de Jan.; 9 de Jan. e 10 de Jan.

C - Ensaio

a) Literatura:

"Tristão de Athayde" - ALB (Americ.-Ed.); ALB (M).

"A Poesla em 1930" - ALB (Americ.-Ed.); ALB (M).

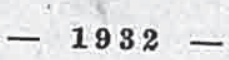

A - Arte Literária

a) Cronica: Crônlcas seleclonadas em 1942 pelo A. para FC (M), sem
Indicaçāo de periódico (15):

"Abril"

"Ca1, ca1, balăo"

"Largo da Concórdia"

"Idillo novo"

"Ritmo de marcha"

b) Poesla:

Poema: "Toada" - GC - parte IV de "Poeslas" - (M);
GC-PC (M).

B - Critica Musical

"O Ditador e a Música" - MDM (LG Miranda); MDM (M).

C - Ensaio

a) Folclore:

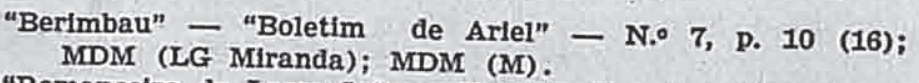

(16) Segundo verificaçăo da pesquisa. 
b) Literatura:

"Luiz Aranha ou a Poesla Preparatoriana" - ALB (M).

A - Arte Literárin

a) Crônica:

Cronlca seleclanada pelo A. em 1942 para FC (M), sem indicação de periódico:

"Fol sonho"

b) Poesia:

Poemas de "A Costela do Grão Căo" in "Grão Căo de Outubro" - GC - parte IV de "Poesias" (M); GC-PC (M.:

"29 Blchos" (out. de 1933)

"Poema tridente" (out. de 1933)

"Os Gatos" (14 de out. de 1933) - (15 de out. de 1933)

"Estanclas" (15 de out. de 1933)

"Dor" (15 de out. de 1933)

"Quarenta anos" (27 de dez. de 1933)

Poemas do "Llvro Azul" in "O Grifo da Morte" - LA parte V de "Poeslas" (M); LA-PC (M):

"Milhōes de rosas" - I

"Retorno sempre" - II

"Mocidade parva" - III

"Quando o rio Madelra" - IV

"Silenclo monótono" - V

B - Ensaio

a) Folclore:

"Música de Felticaria no Brasil", conferêncla na Escola Naclonal de Música, feita em outubro, que fol utilizada por Oneyda Alvarenga, na publicação póstuma que organizou dos estudos de Mário de Andrade sôbre a Música de Feitiçarla brasileira. "Música de Feltiçaria no Brasil" - (M).

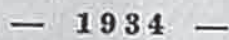

\section{A - Arte Literária}

2) Crônica:

Crônicas selecionadas pelo A. em 1942 para FC (M), sem indicacāo de períódico:

"Voto Secreto"

"Momento Pernambucano" 
B - Ensaio

a) Folclore:

Série de 4 artigos: "Os Congos" - e "Porque os Congos" no "Diário de S. Paulo" a 18 e 25 de mar., 5 de abr. e 8 de malo de 1934; e 15 de mar. de 1935 que serviram através de suas notas orlginais à Oneyda Alvarenga em sua organizacão dos trabalhos de Mário de Andrade para "Danças Dramáticas do Brasil" - vol. II (M).

"Luciano Gallet" - introdução aos "Estudos de Folclore" de L. Gallet" (17) - Carlos Wehrs \& Cia. - RJ.

b) Literatura:

"Amor e Mêdo".

"O Aleijadinho e A. de Azevedo" (18) - RA Ed.; ALB (M).

$-1935-$

A - Arte Literária

a) Crônica:

Selecionada por M. de A. em 1942 para FC (M), sem indicacão de periódico:

"Rel Mômo" - FC (M).

B - Ensaio

a) Folclore:

"A Nau Catarineta" (19) - separata da "Revista do Arquivo Municipal", n. 73 - Dep. de Cultura, SP; suas notas integram "Danças Dramáticas do Brasil", vol. I, organizacāo póstuma por $\mathrm{O}$. Alvarenga.

b) Música:

"Cultura Musical" - discurso de paraninfo da turma de 1935 do Conservatório Musical de Săo Paulo - Dep. de Cultura da Municipalidade, SP -1936 . AMB (M)

$$
-1936-
$$

D - Ensaio

a) Música:

"Anteprojeto de Lingua-padrāo para o Primeiro Congresso da Lingua Nacional Cantada" - Dep. de Cultura, SP (?).

"A Música e a Canção Populares no Brasil" (20) - "Rev. do Arquivo Municipal", SP - Separata n.o 19, ano II jan. - Dep. de Cultura; Distribuicāo mimeografada pela C. de Coop. Intelect. do Ministério do Exterlor; EMB (M).

(17) Segundo a cronologia manuscrita do Autor.

(18) A cronologia feita pelo Autor nada informa sôbre a data de composicão, pols apenas marca duas interrogacōes. A partir da indicacāo da gráfíca usada, pela editôra, concluímos que o trabalho deve ser de 1934. Nâo é, entretanto, afirấ derinitiva.

(19) Segundo a cronologia manuscrita do Autor. cāo de pesquilsa. 


\section{A - Arte Uterária}

a) Cronica:

Seleclonada pelo A. em 1942, sem indicacão de periódico, para FC (M):

"Biblloteconomia"

b) Poesia:

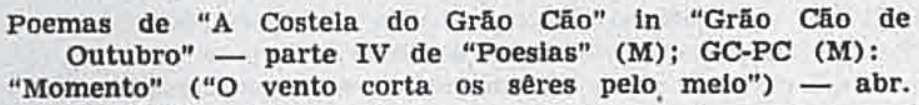

B - Ensalo

a) Artes Plásticas:

"A Capela de Santo António" - "Rev. do Instituto Histórico Nacional", n.o 1 - APB (M).

b) Folclore:

"O Samba rural paulista" - Separata de "Rev. do Arquivo Municipal", n.0 41 - AMB (M).

"Terapeutica musical" - "Namoros com a Medicina" - L. do Globo - Porto Alegre - NM (M).

"Medicina dos excretos" - NM - L. do Globo; NM (M).

c) Música:

"Os compositores e a Lingua Nacional" - Separata dos Anais do I Congresso da Lingua Nacional Cantada em 1937 Dep. de Cultura da Municipalidade, SP; AMB (M).

"A Pronúncia cantada e o problema da nasal, pelos discos" - Separata dos Anais do I Congresso da L. Nacional Cantada em 1937 - Dep. de Cultura da Municipalidade, SP; AMB (M).

"Normas para a boa pronúncia da Lingua Nacional no canto erudito" - Separata da "Rev. do Arquivo Municipal", n.॰ 39 - Dep. de Cultura da Municipalidade.

$$
-1938-
$$

\section{A - Arte Ilterária}

a) Crônica:

Selecionada pelo A. em 1942 para FC (M), sem indicacāo de periódico:

"Conversa à beira do cais" 
b) Poesla:

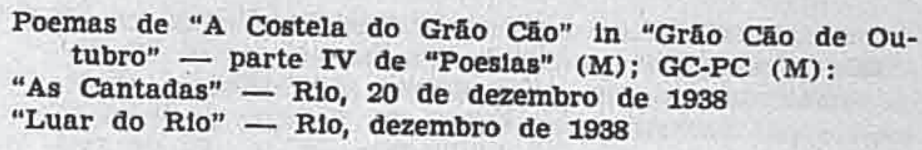

B - Critien Literarla

Artigos de "O Empalhador de Passarinho" (M), sem Indicaçāo de períólico:

"Contos e Contistas" - 13 de set.

"O Parnasianismo" - 2 de set.

\section{C - Critica Musleal}

"As Bachlanas" - "O Estado de S. Paulo", 23 de nov.; MDM (M).

\section{D - Ensalo}

a) Artes Plásticas:

"Curso de Filosofia e História da Arte: Anteprojeto do Serviço do Patrimônio Histórico e Artístico Nacional" Centro de Estudos Folclóricos - Săo Paulo - Mimeografado.

b) Estética:

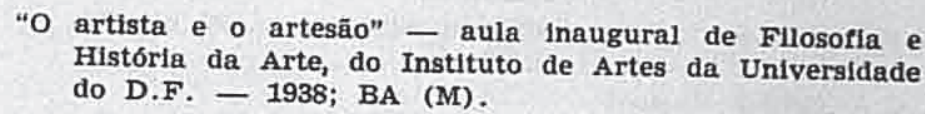
História da Arte, do Instituto de Artes da Universidade do D.F. - 1938; BA (M)

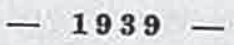

\section{A - Arte Literária}

a) Conto:

$$
\text { "Briga das Pastoras" - PA-OI (M). }
$$

b) Crônica:

Crônicas selecionadas pelo A. em 1942 para FC (M), sem indicaç̄o de períodico (20):

"Brasil e Argentina"

"Sociologia do Botão"

"O dom da voz"

"Problemas de transito"

"Tacacá com tucupi"

"Calor"

"Esquina"

B - Critica ILterária

Artigos de "O Empalhador de Passarinho" - (M), sem indicação de perí́dico: 
"Belo, jovem, forte" - 12 de mar. (v. de Morals)

"Nocăo de responsabllidade" - 19 de fev. (S. Milllet)

"Feltos em Franca" - 26 de mar.

"Uma grande inocência" - 2 de abr. (Folclore)

"A Poesla em pânico" - 9 de abr. (M. Mendes)

"O pintor contista" - 21 de mai. (L. Jardim)

"Três faces do eu" - 8 de mai. (F. Mendes de Almelda e

O. Alvarenga - R. C. Guarnleri)

"Cecilla e a Poesla" - 23 de jul.

"Do cabotinismo" - 23 de jul.

"Uma suave rudeza" - 4 de jun. (Casais Montelro)

"Tasso da Sllveira" - 30 de jul.

"Estrada perdida" - 20 de agost. (T. Vergara)

"A Raposa e o Tostão" - 27 de agost. (Contemporaneos)

"Do Trágico" - 10 de set. (O. de Faria)

"As Três Maria" - 17 de set. (R. de Queirós)

"Romances de um antiquário" -24 de set. (C. Pena)

"A Estrêla sobe" -1 de out. (M. Rebêlo)

"Rlacho Doce" - 12 de set. (J. Lins do Régo)

"Os Caminhos da Vida" - 29 de out. (O. de Faria)

"Repeticão e Mûsica" - 11 de nov. (J. Lins do Rêgo)

"A Psicologia em acão" - 19 de nov. (M. Rebelo)

"A Psicología em análise" - 26 de nov. (Graclliano Ramos et al.)

"Viagem" -26 de nov. (C. Meirelles)

"Literatura Nacional" - 3 de dez.

"Cangerāo" - $10 \mathrm{de} \mathrm{dez.} \mathrm{(Emil} \mathrm{Farhat)}$

"Polemlcas" - 24 de dez. (Estética)

"Amadeu Amaral" - 24 de dez.

\section{C - Critica Musical}

Criticas publlcadas em "O Estado de São Paulo" e reproduzldas na $3 .^{a}$ ediçăo (póstuma) de $M D M-(M)$, in "Novos Artigos":

"Música Popular" - 15 de jan.

"Música Naclonal" - 12 de fev.

"Quarto de tom" - 16 de abr.

"Nacionalismo musical" - 14 de mal.

"Laforgue e Satie" - 9 de jul.

"Sonoras criancas" - 8 de out.

"Francisco Mignone" - 20 de out.

"Teutos, mas músicos" -31 de dez.

D - Ensalo

a) Artes Plásticas:

"Portinarl" - Catálogo - Ed. do Minist. de Educacăo BA (M).

"Do Desenho" - APB (M) (21)

(21) A Ediçāo da Livraría Martins declara ser «Do Desenhos um recorte de fornal, sem data ou indicaçá, encontrado entre os papéis de Mário de Andrade. Na realldade fol escrito para o Estado de São Paulo e reproduzido na seleta de Colaboraçăo Mensal do jornal, Ano I, n.o 8, Abrill-Malo, 1939, pág. 46. 
b) Folclore:

c) Literatura

"As Cheganças" - série de 5 antigos em "O Estado de Săo Paulo", que serviram com suas notas orlginais, a elaboração póstuma dos trabalhos de $M$. de $A$. sobre as Chegancas, por $O$. Alvarenga para "Dancas Dramáticas do Brasil" - vol. I (M).

"Machado de Assis" - ALB (Americ-Ed.); ALB (M).

d) Música :

"Castro Alves" - ALB (Americ-Ed.) ALB (M).

"Evoluçāo Social da Múslca no Brasil" ou "Evolução Socla da Música Brasileira" - Guaira; auxillar na composicâo de "Danças Dramáticas do Brasil" (M). Publicado também em "O Estado de S. Paulo".

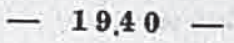

A - Arto Literaria

a) Poesia:

Poema: "Cançăo" - GC in "Grăo Căo de Outubro" - parte IV de "Poeslas" (M); CG-PC (M).

B - Critica Literária

Artigos de "O Empalhador de Passarinho" - (M), sem indlcação de periódico:

"Modernismo" -7 de jan.

"Vaqueiros e cantadores" - 11 de fev.

"Da Obscuridade" - 18 de fev.

"Um critico" - 25 de fev.

"A língua radiofónlea" -3 de fev.

"A lingua viva" - 10 de mar.

"Pintores e pinturas" - i7 de mar. (S. Millet)

"Gabriela Mistral" - 17 de mar.

"A Mulher Ausente" - 21 de abr. (A. Neri)

"Um cancioneiro" - 12 de mat( ( $R$. Couto)

"Frontelras" - 14 de jul. (0. de Faria)

"Salomé" - 28 de jul. (M. del Picchla)

"Saga" - 1 de set. (E. Verissimo)

C - Critica Musical

Criticas publicadas em "O Estado de Săo Paulo" e reproduzidas na 3.s edição de MDM (M) - (postuma), in "Novos Artigos":

"Ernesto Nazaré" - 7 de jan.

"Camargo Guarnieri" - 28 de jan.

"Chiquinha Gonzaga" - 10 de fev.

"Paganinl" - 24 de mar. 
D - Ensalo

a) Literatura:

"Memórlas de um Sargento de Miliclas" - prefácio para
a Edicão de Luxo da Obra (M); ALB (Americ-Ed.); ALB (M).

b) Música:

"A Expressāo Musical nos Estados Unidos" (22) - "Lições da Vida Americana" n.० 3 - Instituto Leusinger BraSll-EE.UU. - RJ; MDM (M).

\section{$-1941-$}

A - Critlea Literária

Artigos de "O Empalhador de Passarinho" (M); sem Indicacāo de períódico:

"Coraç̃o Magoado" - 11 de jul. (H. Lisboa)

"O Balle dos Pronomes" - 7 de out.

"O Desaflo Brasllelro" - 23 de nov. (Folclore)

B - Critica Musical

Criticas publicadas nos "Díários Associados" e incluidas na 2." edicăo de MDM (M); in "Novos Artigos":

"A Modinha e o Lalo" - 28 de jan.

C - Ensalo

"O Desenvolvimento da Modinha" - 6 de fev.

a) Cinema:

"Fantasla" - BA (M),

b) Iiteratura:

"A Volta do Condor" - ALM (Americ-Ed.); ALB (M),

"O Ateneu" - ALB (Americ.-Ed.); ALB (M).

c) Música:

"Romantismo Musical" - BA (M).

\section{A - Arto Literâria}

a) Conto:

Contos publicados em "Contos Novos" (M) - ed. póstuma:

"Frederico Paciência" - 1924/1942

"Primeiro de malo) - 1934/1942

"O poco" - 1938/1942

"O ladrăo" - 1930/1941/1942

"O peru de Natal" - agôsto de 1938/1942

(22) Segundo a cronologia manuscrita do Autor. 
b) Teatro:

$$
\begin{gathered}
\text { "Café" - concepcão melodramática em } 3 \text { atos - 1938/1939/ } \\
1942 \text { - publicação póstuma em - PC (M). }
\end{gathered}
$$

B - Critica Literária

Artigos de "O Empalhador de Passarinho" (M), sem indicaçáo de periódico:

"Mário Neme" - marco de 1942

"Otávio e a Poesia" -8 de janeiro

"Fogo Morto" - 25 de janeiro

\section{C - Critica Muslcal}

Criticas publicadas pelo A. em periódicos e reproduzldas na 3. ${ }^{a}$ edicảo de $M D M(M)$ :

"Espantalho" - 27 de janelro - "Diárlos Assoclados" - SP "Música Brasileira" - 23 de marco - "Diário de Noticlas" - RJ.

"Histórias Musicais" - 15 de abril - "O Estado de $\mathrm{S}$. Paulo" - SP

"Distanciamentos e aproximacōes" - 10 de maio - "O Estado de S. Paulo" - SP.

\section{D - Ensaio}

a) Artes Plésticas:

Incumbêncla e início da pesquisa para o estudo sobre o "Padre Jesuino do Monte Carmelo" para o Servico de Património Histórico e Artístico Nacional - Introducăo do trabalho datada de 31 dez. 1944 - "Rev. do SPHAN", n.॰ 14 - RJ; "Padre Jesuino do Monte Carmelo" (M).

b) Literatura:

"O Movimento Modernista" - conferência lida no Salăo de Cone. da Biblioteca do Min. das Relacōes Exteriores Ed. da Casa do Estudante no "Jornal do Comércio" RJ; ALB (M).

c) Folclore:

"O Folclore no Brasil" - Manual Blbllogr. de Est. Brasil. - RJ — 1949.

d) Música:

"Atualidade de Chopln" - "Rev. do Arquivo Municipal de São Paulo" - Dep. de Cultura; BA (M).

"Evocacāo de Gomes Cardim" - cone. para a festa do 77. aniversário do fundador do Conservatório, promovida pelo Centro Dramático e Musical "Gomes Cardim" a 16 de setembro de 1942 - Ed. da Interv. do Conservatório em G. Siqueira - SP. 


\section{A - Arto Literária}

a) Conto:

de "Contos novos" (M) - Ed. póstuma:

"Vestida de prêto" - Río, 1939 - Săo Paulo, 11 nov. 1943. "Tempo de camisollnha" - 1939/1943.

"Nelson" - 1943.

b) Poesia:

Poemas de "Carro da Miséria" - 29 de dez, 1930 - 11 de out. 1932 - 26 de dez. 1943 - "Lira Paulistana" seguida de "O Carro da Miséria" (M); CM-PC (M):

"O que vem pelos meus olhos" - I

"Meu baralho dos ouros" - II

"Plca-Fumo Rompe-Rasga" - II

"Mas não quero estes zabumbas" - IV

"Plaff! Chegou o carro da Miséria" - V

"Ah eu sel que as trompas fúnebres" - VI

"Tla Miséria" - VII

"Nas ondas do mar eu vou" - VIII

"Oh, năo! multo obrigado" - IX

"Pols então, violão" - $\mathrm{X}$

"Enquanto isso" - XI

"Mas eu, mas eu rapazes" - XII

"Enquanto o mundo for mundo" - XIII

"Vou-me embora, vou-me embora" - XIV

"Estes zabumbas que eu quero" - XV

"Nasce o dla, canta o galo" - XVI

\section{B - Ensaio}

a) Artes Plásticas:

"Lasar Segall" - catálogo - Min. da Educacāo - APB (M). "Arte Inglêsa" - BA (M).

b) Literatura:

"Aspectos da Literatura Brasileira" - Colecão Joaquim Nabuco (Americ-Ed.) - RJ-ALB (M).

"Segundo Momento Pernambucano" - 9 de jul. 1943 - prefácio para a poesia de Otávio de Freltas Jr., - Ed. da Casa do Estudante - Col. Ensalos do Nosso Tempo "Aspectos da Literatura Brasilelra" - Col. Joaquim Nabuco (Amer-Ed.) - RJ - 1943 - ALB (M).

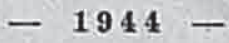

\section{A - Arte Literária}

a) Conto:

"Atrás da Catedral de Ruão" - CN (M). 
b) Poesia:

\section{B - Critica Musical}

Poemas de "O Carro da Miséria" - "Lira Paulistana" seguida de "O Carro da Miséria" (M); LP-PC (M).

"Meditacão sôbre o Tletê" - 30 set. 1944 - 12 fev. 1945.

"Acalanto para Luis Carlos" (23).

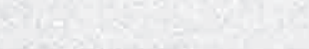 \\ A - Arte Literária}

Artigos publicados pelo A. em jornals e reproduzidos na 3. a - edicão (póstuma) de MDM (M):

"São cantos de guerra" - 16 de jan. - "Correlo de Manhã" - RJ.

"Romain Rolland, músico" - 24 de abr. - "Correlo da Manhã" - RJ

"Chopin" - 3 de set. - "Dlários de Noticias" - RJ.

\section{- sem data -}

a) Poesia:

Poemas de "Lira Paulistana" - 1944 (23). As edicāo nāo fornecem data de composicão - "Lira Paulistana" seguida de "O Carro da Miséria" - (M); LP-PC (M):

"Minha viola bonita"

"São Paulo pela noite"

"Garôa de meu São Paulo"

"Vaga um céu indeciso..."

"Ruas de meu São Paulo"

"Abre-te a boca e proclama"

"Esse homem que vai sòzinho"

"Meus olhos se enchem de lágrimas"

"O bonde abre a viagem"

"Eu nem sel se vale a pena"

"O céu claro tão largo..."

"Tua imagem se apaga..."

"Numa cabeleira pesada"

"Na rua Barāo de Itapetininga"

"Beijos, mais beijos"

"Silêncio em tudo"

"Ballam em saltos fluidos"

"A Catedral de São Paulo"

"Agora eu quero cantar"

"Na rua Aurora eu nasci"

1944, pols a 21 de fevereiro de 1945 Mărio es poemas de Ira Paulistana seja de a obra. A carta fol recentemente publica escreve a Dantas Motta, mandando-lhe Gerais, Belo Horizonte, ediç̃o dedicada a Mário «Suplemento Literálos de Minas n. 93, Ano III. 
"Vleste de um futuro selvagem"

"Moca linda, bem tratada"

"Quando eu morrer"

"Num filme de B. de Mille"

"Entre o vidrilho das estrelas dúblas"

"Nunca estará sòzinho"

B - Critica Mrusical

Artigos publicados pelo A., em jornals e reproduzidos na 3. a edicăo (póstuma) de $\mathrm{MDM}^{\circ}(\mathrm{M})$ :

"Oferta Musical"

"Hino às Nacōes Unidas"

\section{BIB I I O G R F I A}

ANDRADE, Márlo de - Obra completa nas ediçōes focallzadas pelo trabalho.

BANDEIRA, Manuel - Cartas a Manuel Bandeira - Coletanea - Clássicos Braslleiros - Ediçóes de Ouro - Rlo de Janelro - 1966.

FERNANDES, Ligia - Mário de Andrade escreve cartas a Alceu, Meyer o outros - Coletanea - Editôra do Autor - Rio de Janeiro - 1968.

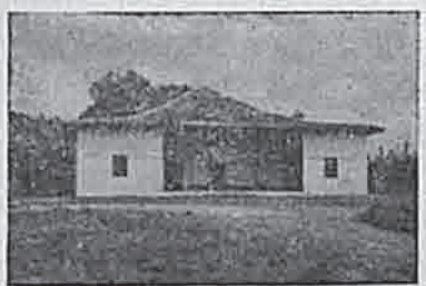

